\title{
Oestrogen inhibition reverses pulmonary arterial hypertension and associated metabolic defects
}

\author{
Xinping Chen ${ }^{1}$, Eric D. Austin ${ }^{2}$, Megha Talati $^{1}$, Joshua P. Fessel ${ }^{1,3}$, \\ Eric H. Farber-Eger ${ }^{4,5}$, Evan L. Brittain ${ }^{1,5}$, Anna R. Hemnes ${ }^{1}$, \\ James E. Loyd ${ }^{1}$ and James West ${ }^{1}$
}

Affiliations: ${ }^{1}$ Dept of Medicine, Vanderbilt University Medical Center, Nashville, TN, USA. ${ }^{2}$ Dept of Pediatrics, Vanderbilt University Medical Center, Nashville, TN, USA. ${ }^{3}$ Dept of Pharmacology, Vanderbilt University Medical Center, Nashville, TN, USA. ${ }^{4}$ Center for Human Genetics Research, Vanderbilt University, Nashville, TN, USA. ${ }^{5}$ Vanderbilt Translational and Clinical Cardiovascular Center, Vanderbilt University Medical Center, Nashville, TN, USA.

Correspondence: James West, Vanderbilt University, 1161 21st Ave S, T-1218 MCN, Nashville, TN 37232-2650, USA. E-mail: j.westavanderbilt.edu

@ERSpublications

Oestrogen inhibition reverses BMPR2-related pulmonary arterial hypertension and associated metabolic defects http://ow.ly/ir6Y30b2WLH

Cite this article as: Chen $\mathrm{X}$, Austin $\mathrm{ED}$, Talati $\mathrm{M}$, et al. Oestrogen inhibition reverses pulmonary arterial hypertension and associated metabolic defects. Eur Respir J 2017; 50: 1602337 [https://doi.org/10.1183/ 13993003.02337-2016].

ABSTRACT Increased oestrogen is a strong epidemiological risk factor for development of pulmonary arterial hypertension (PAH) in patients, associated with metabolic defects. In addition, oestrogens drive penetrance in mice carrying mutations in bone morphogenetic protein receptor type II (BMPR2), the cause of most heritable PAH. The goal of the present study was to determine whether inhibition of oestrogens was effective in the treatment of PAH in these mice.

The oestrogen inhibitors fulvestrant and anastrozole were used in a prevention and treatment paradigm in BMPR2 mutant mice, and tamoxifen was used for treatment. In addition, BMPR2 mutant mice were crossed onto oestrogen receptor (ESR)1 and ESR2 knockout backgrounds to assess receptor specificity. Haemodynamic and metabolic outcomes were measured.

Oestrogen inhibition both prevented and treated PAH in BMPR2 mutant mice. This was associated with reduction in metabolic defects including oxidised lipid formation, insulin resistance and rescue of peroxisome proliferator-activated receptor- $\gamma$ and CD36. The effect was mediated primarily through ESR2, but partially through ESR1.

Our data suggest that trials of oestrogen inhibition in human PAH are warranted, and may improve pulmonary vascular disease through amelioration of metabolic defects. Although fulvestrant and anastrozole were more effective than tamoxifen, tamoxifen may be useful in premenopausal females, because of a reduced risk of induction of menopause.

This article has supplementary material available from erj.ersjournals.com

Received: May 042016 | Accepted after revision: April 152017

Support statement: These studies were supported by National Institutes of Health (NIH) grants NIH P01 HL108800, NIH R01 HL 095797 and HL 122417 and NIH K08 HL121174; a Parker B. Francis fellowship (J.P. Fessel); American Heart Association Fellow to Faculty Award \#13FTF16070002 (E.L. Brittain); and the Gilead Sciences Research Scholars Program in Pulmonary Arterial Hypertension (E.L. Brittain). The Seahorse Bioscience Extracellular Flux Analyzer used in the present study is housed and managed within the Vanderbilt High-Throughput Screening Core Facility, an institutionally supported core, and was funded by NIH shared instrumentation grant S10 OD018015. Funding information for this article has been deposited with the Crossref Funder Registry.

Conflict of interest: Disclosures can be found alongside this article at erj.ersjournals.com

Copyright OERS 2017 


\section{Introduction}

Pulmonary arterial hypertension (PAH) is a disease that includes pulmonary vascular endothelial dysfunction, occlusion and dropout of the small and medium-sized pulmonary arteries and hypertrophy and proliferation of smooth muscle and adventitial cells. These combine to give a progressively worsening elevation of pulmonary vascular resistance $[1,2]$. This eventually leads to right heart failure and death; no current therapy is curative.

The majority of cases of the heritable form of $(\mathrm{H}) \mathrm{PAH}$ are associated with mutations in bone morphogenetic protein receptor type II (BMPR2), the type 2 receptor for the BMP pathway [3]. In addition, BMPR2 is suppressed in most other forms of PAH, even in the absence of mutation [4]. Mice with BMPR2 mutation or deletion will spontaneously develop PAH [5-7]. However, penetrance in both mice and humans with BMPR2 mutation is incomplete: only $20 \%$ of humans with BMPR2 mutation develop clinical PAH [8].

The strongest epidemiologic risk factor for many forms of PAH is female sex [9]. While only $20 \%$ of humans with a BMPR2 mutation develop PAH, there is a striking difference according to sex: $43 \%$ of females versus $14 \%$ of males with a BMPR2 mutation develop PAH in their lifetime [10]. Consistent with this finding, we demonstrated that oestrogen metabolism was a strong predictor of penetrance in HPAH: females who preferentially metabolised oestrogens into 16-oestrogens such as $16 \alpha \mathrm{OHE} 1$ developed PAH, whereas females who preferentially metabolised oestrogen into 2- or 4-oestrogens did not [11-13]. Oestrogen metabolism drives penetrance in males, although not to the same degree as in females [14].

The mechanism for female preponderance of human disease remains poorly explained, in part because in classical rodent models of PAH such as hypoxia and monocrotaline, oestrogen was found to be protective [15]. This may be associated with a difference between endogenous and exogenous oestrogens; potential differences include location of production (significant oestrogens are made in the pulmonary vasculature) and the cyclic nature of natural oestrogens [16]. Our data show that, as in human patients, BMPR2 mutant mice treated with 16 $\alpha \mathrm{OHE} 1$ developed PAH with higher penetrance and severity [14], more closely recapitulating the human phenomenon than other models. Our prior work suggested that $16 \alpha \mathrm{OHE} 1$ promotes insulin resistance and other metabolic problems $[14,17]$. Consistent with this finding, metabolic defects have been increasingly associated with PAH [18-20], and we have demonstrated that they exacerbate PAH in BMPR2 mutant mice $[21,22]$. Although the mechanism linking metabolic defects to $\mathrm{PAH}$ is not clear, it may be associated with vascular dysfunction, proliferation or production of damaging superoxides [23].

Because in classical PAH models oestrogen inhibition is harmful, the current study sought to determine whether inhibition of endogenous oestrogens was therapeutically effective at preventing or reversing established BMPR2-related PAH, and whether this was associated with improved metabolic metrics such as insulin resistance and oxidised lipids. Safety of anastrazole in postmenopausal PAH patients, with suggestion of efficacy, has already been established in a small trial [24]. Demonstration of efficacy and mechanism is thus a final step necessary in preclinical models to validate the translation of this chain of research to patients.

\section{Methods \\ Oestrogen inhibition experiments}

We used the Rosa26-rtTA2 $\times \mathrm{TetO}_{7}-\mathrm{Bmpr}^{\mathrm{R} 899 \mathrm{X}} \mathrm{FVB} / \mathrm{N}$ mice, as previously described $[25,26]$, called Rosa26-Bmpr2 $2^{\mathrm{R} 899 \mathrm{X}}$ or Bmpr2 ${ }^{\mathrm{R} 899 \mathrm{X}}$ for brevity. R899X is an arginine-to-termination mutation at amino acid 899 in the BMPRII tail domain found in family US33 [6]. Expression of the transgene occurs in all tissue types, but only after initiation of doxycycline.

Adult female Rosa26-only or Rosa26-Bmpr2 ${ }^{\text {delx4+ }}$ mice at a starting age of 8-10 weeks had transgene activated with doxycycline at $0.2 \mathrm{mg} \cdot \mathrm{g}^{-1}$, and received either vehicle (see later) or treatment. No mice in these experiments received exogenous $16 \alpha \mathrm{OHE} 1$. Mice were randomised to a treatment group, and the individual performing phenotyping was blinded to group, as were the institutional specialty labs performing, for instance, insulin counts. Fulvestrant (Selleck Chemicals, Houston, TX, USA) was dissolved in ethanol to $100 \mathrm{mg} \cdot \mathrm{mL}^{-1}$. Anastrozole (Sigma, St Louis, MO, USA) was dissolved in ethanol to $2 \mathrm{mg} \cdot \mathrm{mL}^{-1}$. Inhibitor solution was diluted in peanut oil and injected subcutaneously into mice daily. Fulvestrant dosage was $200 \mu \mathrm{g} \cdot \mathrm{mouse}^{-1} \cdot \mathrm{day}^{-1}\left(\sim 6 \mathrm{mg} \cdot \mathrm{kg}^{-1}\right)$ and anastrozole dosage was $10 \mu \mathrm{g} \cdot \mathrm{mouse}^{-1} \cdot$ day $^{-1}\left(\sim 0.3 \mathrm{mg} \cdot \mathrm{kg}^{-1}\right)$. Medroxyprogesterone 17 -acetate (MPA; Sigma) was dissolved in ethanol to $50 \mathrm{mg} \cdot \mathrm{mL}^{-1}$. MPA solution was diluted in peanut oil and injected intramuscularly into mice at a dosage of $1 \mathrm{mg} \cdot \mathrm{mouse}^{-1}$ every 3 weeks $\left(30 \mathrm{mg} \cdot \mathrm{kg}^{-1}\right.$ per 3 weeks). Tamoxifen (Sigma) was dissolved in ethanol to $100 \mathrm{mg} \cdot \mathrm{mL}^{-1}$ and diluted with peanut oil before injection into mice. Injection dosage was $1 \mathrm{mg} \cdot \mathrm{mouse}^{-1} \cdot \mathrm{day}^{-1}\left(\sim 30 \mathrm{mg} \cdot \mathrm{kg}^{-1} \cdot \mathrm{day}^{-1}\right)$. 
Drug dosages used were converted from human dosages according to the method of REAGAN-SHAW et al. [27], using proportional body surface areas; this results in increasing dosages from human patient to mouse per unit weight by a factor of $\sim 12$. Doses used are well matched to those used in recent human and animal studies; for a $50 \mathrm{~kg}$ human female, our dose would be equivalent to $1.2 \mathrm{mg} \cdot \mathrm{day}^{-1}$, similar to the $1.0 \mathrm{mg} \cdot \mathrm{day}^{-1}$ used in the recent pilot study in human PAH patients [24].

For prevention experiments, animals started received the drug at time of doxycycline induction. For reversal experiments, animals received doxycycline only for 4 weeks, followed by an additional 2 weeks of both doxycycline and treatment (or vehicle).

After 6 weeks, animals underwent echocardiography, followed on the next day by haemodynamic phenotyping and tissue collection.

\section{Echocardiography and haemodynamic phenotyping}

Two-dimensional echocardiography was performed using Vivo 770 High-Resolution Image System (VisualSonics, Toronto, Canada). Echocardiograms including B-mode, M-mode and spectral Doppler images were obtained the day prior to sacrifice under isoflurane anaesthetic. Velocity time integral and heart rate were measured in the ascending aorta, and diameter measured in the same location. Stroke volume (SV) was derived using the formula $S V=((\pi 2 / 4) \times($ aortic velocity time integral $)$, where $\pi=$ aortic diameter. Cardiac output $(\mathrm{CO})$ was derived using the formula $\mathrm{CO}=\mathrm{SV} \times$ heart rate $[28,29]$.

Haemodynamic phenotyping was performed as previously described $[6,25]$. Briefly, mice are anaesthetised with tribromoethanol, systemic pressure checked using a tail cuff and then closed-chested intrajugular right cardiac catheterisation is performed.

\section{Plasma oestradiol measurements}

Four female mice from each treatment were randomly chosen for oestradiol measurements. $25 \mu \mathrm{L}$ of plasma was dispensed into oestradiol ELISA plates in triplicate (ES180S; Calbiotech, El Cajon, CA, USA). Oestradiol ELISA was performed according to manufacturer's instructions; the absorbance at $450 \mathrm{~nm}$ was read using a microplate reader (model 680; Bio-Rad, Hercules, CA, USA). The concentration of plasma oestradiol level was calculated and presented as $\mathrm{pg} \cdot \mathrm{mL}^{-1}$ from the standard curve.

\section{ESR1/ESR2 $\times$ Bmpr2 ${ }^{R 899 X}$ experiments}

Oestrogen receptor (ESR)1 or ESR2 knockout mice were purchased from the Jackson Laboratory (Sacramento, CA, USA). They were firstly crossed with Rosa26 mice with C57BL/6 background. Then they were crossed with Rosa-R899X mice with FVB/N background. Controls (Rosa26-Bmpr2R899X only) were phenotyped on the same days as the ESR1 and ESR2 knockouts, and are a different group of animals than those used in any other experiment (in no experiment were control values "re-used"). Otherwise, experiments were conducted exactly as for oestrogen inhibition experiments.

\section{Vessel muscularisation}

Paraffin-embedded mouse lung sections were prepared as described previously. Slides were incubated with mouse monoclonal $\alpha$-smooth muscle actin (SMA) antibody (1:200; Dako, Carpinteria, CA, USA) overnight at $4^{\circ} \mathrm{C}$. After three washes with PBS, the slides were treated with Alexa 488 fluorescent secondary antibody (1:1000; Invitrogen, Carlsbad, CA, USA) for $1 \mathrm{~h}$ at room temperature. After three washes with PBS, the slides were air dried and mounting medium was added (Vector Laboratories, Burlingame, CA, USA) and covered with cover glass. SMA-positive vessels were counted under $10 \times$ field using a Nikon Eclipse 90i upright fluorescent microscope (Belmont, CA, USA) for 10 randomly chosen fields per mouse.

\section{Western blotting}

Tissues were homogenised in $500 \mu \mathrm{L}$ of radioimmunoprecipitation assay buffer (PBS, $1 \%$ ipegal, $0.5 \%$ sodium deoxycholate, $0.1 \%$ sodium dodecyl sulfate (SDS)) with protease and phosphatase inhibitor cocktail (Sigma). Tissues were centrifuged at $4^{\circ} \mathrm{C}(15000 \times g, 15 \mathrm{~min})$ and protein concentration was determined by Bradford microassay (Bio-Rad) on the supernatant. Equal amounts of protein extracts were denatured at $95^{\circ} \mathrm{C}$ in a denaturing sample buffer. Protein from each sample $(20 \mu \mathrm{g})$ was separated by electrophoresis in $4-12 \%$ Bis-Tris gel and transferred onto a polyvinylidene difluoride membrane; running buffers were either NuPage SDS Running Buffer (Thermo Scientific, Rockford, IL, USA) or TRIS/glycine/ SDS buffer (Bio-Rad). The membrane was blocked for $1 \mathrm{~h}$ at room temperature with PBS containing 5\% nonfat dry milk and $0.05 \%$ Tween- 20 and probed overnight at $4^{\circ} \mathrm{C}$ with primary rabbit polyclonal antibody against peroxisome proliferator-activated receptor (PPAR) (1:1000 dilution; Abcam, Cambridge, MA, USA), CD36 (1:1000 dilution; Novus Biologicals, Litteton, CO) and $\beta$-actin (1:1000, Abcam, 
Cambridge, MA). The membrane was then incubated at $37^{\circ} \mathrm{C}$ for $1 \mathrm{~h}$ with horseradish peroxidase-labelled donkey antimouse immunoglobulin secondary antibody (1:5000 dilution; Santa Cruz Biotechnology, Santa Cruz, CA, USA). Horseradish peroxidase was detected using the SuperSignal West Pico Chemiluminescent Substrate (Thermo Scientific). Blots were imaged using either a Bio-Rad ChemiDoc Touch Imaging System or an Alpha Innotech Digital Imaging System. Densitometry was performed using ImageJ (public domain software published by the National Institutes of Health).

\section{Detection of mitochondrial superoxide}

Mitochondrial superoxide was detected using MitoSox Red (Molecular Probes, Eugene, OR, USA). Mouse pulmonary microvascular endothelial cells (PMVECs) (wild-type orBMPR2R899X) and transgene induction were conducted as previously reported. The cells were grown to $50-80 \%$ confluence on chamber slides. MitoSOX was added to a final concentration of $0.5 \mu \mathrm{M}$, Hoechst stain was added to a final concentration of $0.1 \mu \mathrm{g} \cdot \mathrm{mL}^{-1}$. Cells were placed in an incubator for $20 \mathrm{~min}$ at $37^{\circ} \mathrm{C}$ and then washed three times with Hanks' balanced salt solution containing calcium and magnesium. Mounting medium (Vector Laboratories) was added to the slides and covered with coverslips. The digital images were taken using a Nikon Eclipse 90i upright fluorescent microscope with an 100× oil immersion objective lens.

\section{Measurement of mitochondrial oxygen uptake}

Wild-type and BMPR2 ${ }^{\mathrm{R} 899 \mathrm{X}}$ murine PMVECs were harvested and cultured from the Immortomouse background, as previously described [30]. $72 \mathrm{~h}$ prior to experiments, cells were transitioned to $37^{\circ} \mathrm{C}$, and doxycycline $\left(300 \mathrm{ng} \cdot \mathrm{mL}^{-1}\right)$ was added to induce transgene expression. For the $24 \mathrm{~h}$ prior to analysis, cells were treated with $1 \mu \mathrm{M} 16 \alpha \mathrm{OHE} 1$ or vehicle. Cells were washed in basal assay medium (Seahorse Biosciences, North Billerica, MA, USA). $1 \mathrm{~h}$ prior to analysis, cells were equilibrated in a carbon dioxide-free incubator in basal assay medium supplemented with glucose $\left(1 \mathrm{~g} \cdot \mathrm{L}^{-1}\right)$, L-glutamine $(2 \mathrm{mM})$ and sodium pyruvate $(1 \mathrm{mM})$ at $\mathrm{pH}$ 7.4. Cells were then analysed in the Seahorse XFe96 Extracellular Flux Analyzer using the mito stress test protocol with the following reagent concentrations (optimised for these analyses in separate experiments): oligomycin $(2.5 \mu \mathrm{M}$ final well $)$, FCCP $(0.5 \mu \mathrm{m}$ final well $)$, FCCP $(0.5 \mu \mathrm{m}$ final well, total $1 \mu \mathrm{M})$ and rotenone and antimycin $\mathrm{A}(0.5 \mu \mathrm{M}$ final well $)$ at the manufacturer's recommended concentrations. Data are reported as the average of five to eight wells per individual condition in each experiment, with experiments performed in duplicate with $70 \mathrm{~K}$ PMVECs per well.

\section{Measurement of Glut4 mobilisation in response to insulin}

Glut4-GFP expression vector was purchased from OriGene (Rockville, MD, USA). Cells were transfected with Lipofectamine 2000 reagent (Invitrogen) according to the manufacturer's instructions. Transfection solutions were replaced with fresh medium $4 \mathrm{~h}$ after transfection, and cells were treated with $1 \mu \mathrm{M}$ $16 \alpha \mathrm{OHE} 1$ or vehicle for $18 \mathrm{~h}$. The cells were then serum-starved for $6 \mathrm{~h}$, stimulated with $10 \mathrm{nM}$ insulin for $1 \mathrm{~h}$, fixed, washed and stained for 4',6-diamidino-2-phenylindole (DAPI) and DY-554 phalloidin (red). Coverslips were mounted in Vectashield mounting medium (Vector Laboratories) and observed under a microscope.

Immunohistochemical analysis of isoketal protein adducts and ceramides in murine lung Immunolocalisation of isoketal protein adducts and ceramides was performed on murine lung sections. Tissue sections were deparaffinised, rehydrated and treated with $0.3 \%$ hydrogen peroxide as described previously. For isoketal staining, sections were incubated in $0.1 \mathrm{M} \mathrm{PBS}(\mathrm{pH} 7.4)$ containing 5\% normal mouse serum and $5 \%$ bovine serum albumin (BSA) for $30 \mathrm{~min}$ at room temperature to block nonspecific binding of the secondary antibody. Sections were incubated with $5 \mu \mathrm{g} \cdot \mathrm{mL}^{-1} \mathrm{D} 11 \mathrm{ScFv}$ (isoketal antibody) for $2 \mathrm{~h}$ at room temperature and then incubated with horseradish peroxidase (HRP)-labelled anti-E tag (1:500 dilution; GE Healthcare, Pittsburgh, PA, USA) for $2 \mathrm{~h}$ at room temperature. For ceramide staining, antigen retrieval was performed in $10 \mathrm{mM}$ citrate buffer. The sections were blocked with 5\% BSA, followed by incubation with ceramide antibody (Enzo Life Sciences, Farmingdale, NY, USA) overnight at $4^{\circ} \mathrm{C}$. The following day, the sections were incubated with biotinylated secondary antibody followed by incubation with HRP-conjugated streptavidin. Diaminobenzidine was used as a substrate for HRP (Vector Laboratories). The sections were dehydrated and mounted in Cytoseal XYL (Richard-Allan Scientific, MI, USA) for light microscopic examination.

\section{Statistical methods}

Statistical tests were performed using the JMP programme (SAS, Cary, NC, USA). One-way or multiple ANOVA was used to determine effects of interacting variables, with post hoc Fisher's least significant difference (LSD) used to determine differences between individual groups. Significance of correlations were established using correlation z-test. 
Animal use approval

The institutional animal care and use committee at Vanderbilt University (Nashville, TN, USA) approved all animal studies.

\section{Results}

Oestrogen inhibition prevents pulmonary hypertension in BMPR2 mutant mice

Having previously shown that $16 \propto \mathrm{OHE} 1$ amplifies $\mathrm{PAH}$, we first sought to determine whether oestrogen inhibition, or androgen exposure were protective, and whether they worked synergistically. For oestrogen inhibition, we used the combination of anastrozole and fulvestrant, as commonly used for oestrogen suppression in human breast cancer. We used them in combination only, rather than independently, because the goal of this initial study was to determine without the strongest possible pharmacological signal if inhibition of oestrogen signalling was protective in this model. Control (Rosa26 only) or Rosa26-Bmpr2 $2^{\mathrm{R} 899 \mathrm{X}}$ mice were fed doxycycline at $0.2 \mathrm{~g} \cdot \mathrm{kg}^{-1}$ for 6 weeks (a time in which Bmpr2 ${ }^{\mathrm{R} 899 \mathrm{X}}$ mice will typically develop elevated right ventricular systolic pressure (RVSP) [25]), and then each genotype was split into four groups: plus or minus the androgen MPA ( $1 \mathrm{mg} \cdot \mathrm{mouse}^{-1}$ every 3 weeks) and plus or minus a combination of the aromatase inhibitor anastrozole $\left(10 \mu \mathrm{g} \cdot \mathrm{mouse}^{-1} \cdot \mathrm{day}^{-1}\right)$ and the oestrogen receptor inhibitor fulvestrant $\left(200 \mu \mathrm{g} \cdot \mathrm{mouse}^{-1} \cdot \mathrm{day}^{-1}\right)$ (anastrozole/fulvestrant). By multiple-factor ANOVA, use of MPA had no significant effect on any variable measured, and so for the remainder of the study these results were grouped with the non-MPA animals. Furthermore, the results are not changed if MPA-exposed animals are excluded.

Use of anastrozole/fulvestrant was effective in suppressing oestrogen signalling, as demonstrated by a strong reduction in uterus weight (figure 1a). As expected, Bmpr2 mutant mice treated with vehicle had elevated RVSP, averaging $35 \mathrm{mmHg}$, and $\sim 50 \%$ penetrance (figure $1 \mathrm{~b}$ ). RVSP is variable in $\mathrm{Bmpr} 2^{\mathrm{R} 899 \mathrm{X}}$ mice because pulmonary vascular resistance is driven by loss and narrowing of vessels, rather than constriction [25]. Use of anastrozole/fulvestrant prevented most of the increase in RVSP in Bmpr2 ${ }^{\mathrm{R} 899 \mathrm{X}}$ mice, with RVSP averaging $27 \mathrm{mmHg}$ in the treatment group, and a penetrance of $\sim 10 \%(\mathrm{p}<0.0001$ compared to vehicle). There was no effect on cardiac output in any group (figure 1c). Fulton index (online supplementary figure S1) is not informative in this model; we have previously published that the right ventricle in Bmpr2 mutant mice (and patients) has an impaired hypertrophic response [19].

Oestrogen inhibition with anastrozole/fulvestrant nearly normalised muscularised vessel counts (figure 1d). Because we have previously shown increased oxidative stress as a marker of the metabolic defects in Bmpr2 mutant mice, we performed immunohistochemistry for oxidised lipids, and found increased oxidised lipid in the vessel wall in Bmpr2 mutant mice; however, this was normalised by oestrogen inhibition (red arrows in figure 1e). Oestrogen inhibition does not appear to reduce oxidised lipid in infiltrating inflammatory cells (figure 1e). We have previously shown an increase in accumulation of the toxic lipid ceramide with Bmpr2 mutation [31] as part of metabolic dysfunction. Ceramide was once again increased in the vascular walls of Bmpr2 mutant mice, and this was reduced by anastrozole/fulvestrant (figure 1f).

\section{Oestrogen inhibition reverses established PAH in BMPR2 mutant mice}

Because reversal of established disease is particularly relevant to the PAH patient population, we allowed Bmpr2 mutant mice to develop PAH for 6 weeks, and then treated them with either anastrozole/ fulvestrant or with the somewhat weaker oestrogen receptor antagonist tamoxifen for an additional 4 weeks. Tamoxifen was added because it can be used in premenopausal females safely without inducing menopause.

As expected, tamoxifen did not impact uterine weights, but anastrozole/fulvestrant reduced uterus weights (figure 2a). Use of anastrozole/fulvestrant reduced plasma oestrogen levels $\sim 3.5$-fold (online supplementary figure S2a). Although, as expected, tamoxifen did not impact circulating oestrogen, it did reduce expression of known oestrogen targets FHL1 and SNAT2 [32] in lung by 50\% and 35\%, respectively (online supplementary figure S2b).

Vehicle-treated Bmpr2 ${ }^{\mathrm{R} 899 \mathrm{X}}$ mice had penetrance and pressures comparable to previous experiments, which were largely reversed by treatment with anastrozole/fulvestrant, but with less effect by tamoxifen (figure $2 \mathrm{~b}$ ). Counts of muscularised small vessels showed a strong increase in Bmpr2 ${ }^{\mathrm{R} 899 \mathrm{X}}$ mice, with modest reduction with tamoxifen, and normalisation with anastrozole/fulvestrant (figure 2c). Ceramide was increased in the vascular walls of Bmpr2 mutant mice, and this was reduced by anastrozole/ fulvestrant, but was not apparent in tamoxifen (figure $2 \mathrm{~d}$ ).

\section{Knockout of either ESR1 or ESR2 partially protects BMPR2 mutant mice}

Because pharmacological methods to inhibit oestrogen receptors may lack specificity and vary by cell type, we used genetic knockouts to attempt to determine whether the oestrogen effect was mediated through 

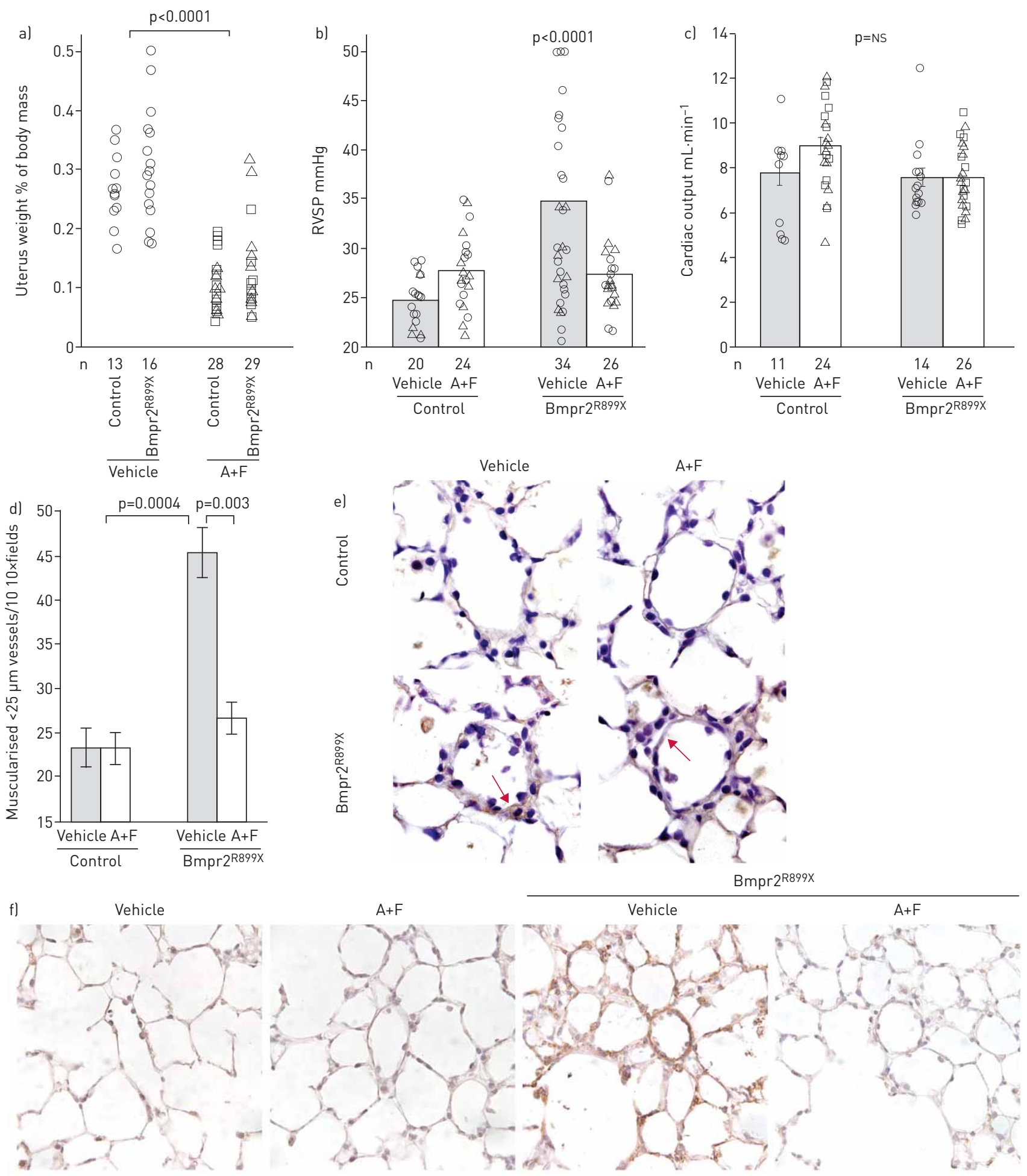

FIGURE 1 a) Anastrozole and fulvestrant $(A+F)$ reduce uterine weights in mice ( $p<0.0001$ ) as expected; by multiple ANOVA, R899X mutation did not have an effect on uterine weights. Each symbol represents the measurement from one mouse. b) A+F delivered in osmotic pumps through the final 4 weeks of 6 weeks' BMPR2 ${ }^{\text {R899X }}$ transgene induction prevents development of elevated right ventricular systolic pressure (RVSP) (p<0.0001 by multiple ANOVA, using transgene and drug as variables). Each symbol represents a value from one mouse. Mice represented by triangles received the androgen medroxyprogesterone acetate (MPA) in addition, which did not impact RVSP, so these data have been not been separated. Mice were age-matched and controls were tested contemporaneously for each group. c) Cardiac outputs from echocardiography were not significantly changed by either A+F treatment or Bmpr2 mutation. d) A+F nearly normalised the increase in muscularised vessels normally seen in BMPR2 R899X mice. By multiple ANOVA considering BMPR2 mutation and treatment as factors, BMPR2 mutation increases muscularised vessels $(p=0.0004)$, while $A+F$ decrease them, specifically in BMPR2 mutant mice $(p=0.003)$. e) Staining for oxidised lipids demonstrates increased oxidative stress in BMPR2 ${ }^{R 899 X}$ mice, normalised with $\mathrm{A}+\mathrm{F}$ (arrows). f) Ceramide (toxic lipid) staining (brown) is increased in lungs from BMPR2 ${ }^{\text {R899X }}$ mice and reduced by A+F. NS: nonsignificant. 

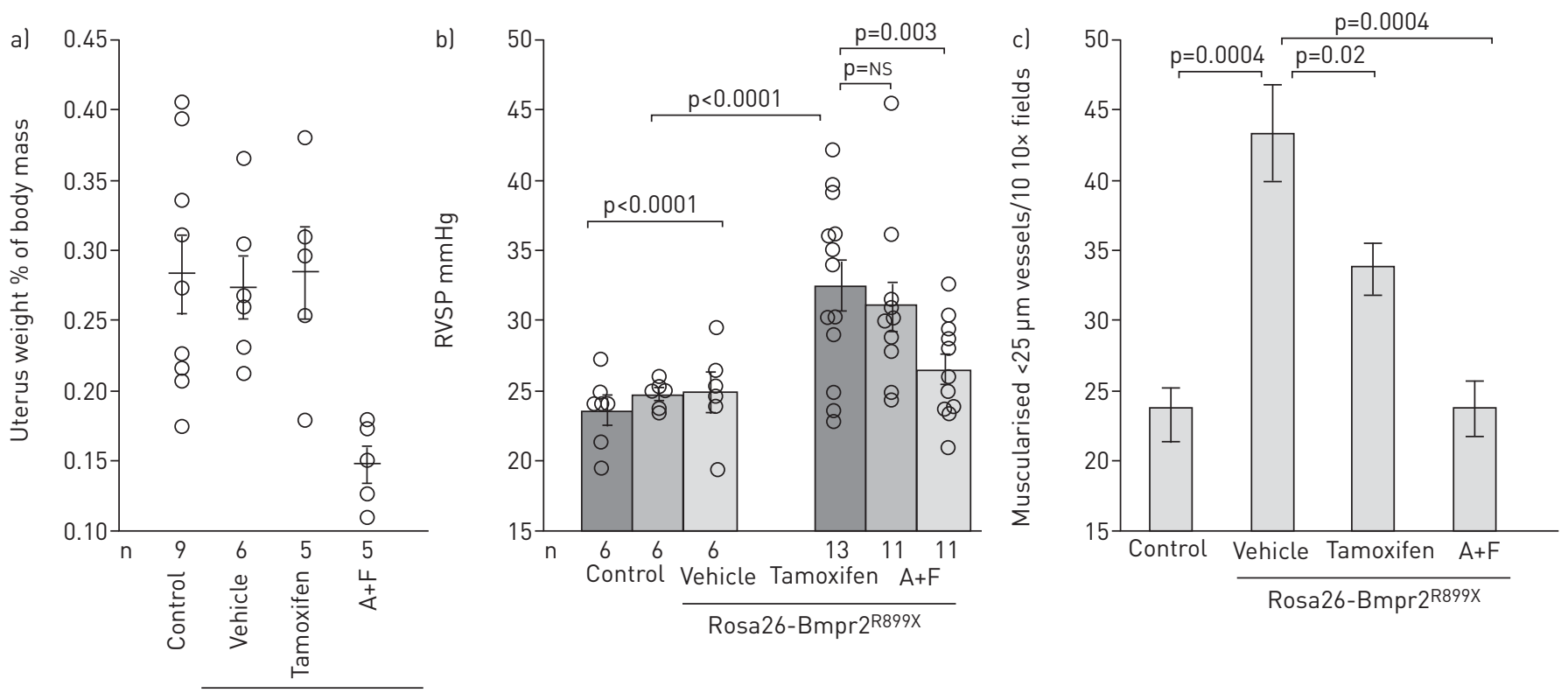

Rosa26-Bmpr2R899X

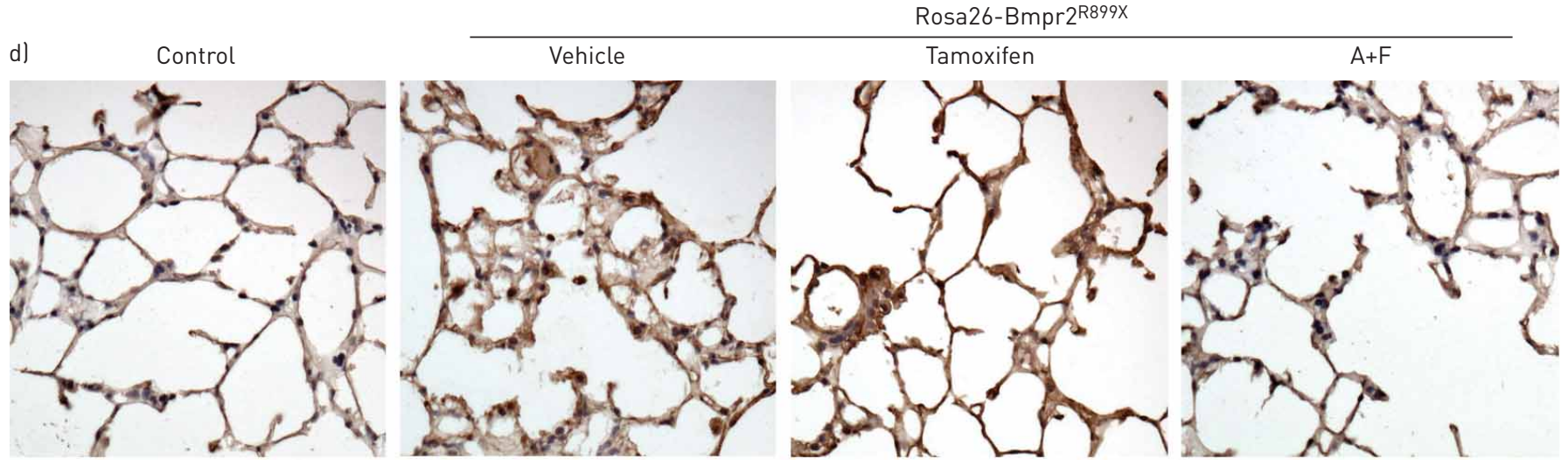

FIGURE 2 a) Anastrozole and fulvestrant $(A+F)$, but not tamoxifen used as treatment reduces uterine weights in mice ( $p=0.002$ for comparison to control; $p=0.007$ for comparison to vehicle). Each symbol represents the measurement from one mouse; data are presented as median \pm SEM. $b$ ) $A$ $+F$ delivered in osmotic pumps through the final 4 weeks of 10 weeks' BMPR2 ${ }^{\mathrm{R} 899 \mathrm{X}}$ transgene induction reverses development of elevated right ventricular systolic pressure (RVSP) ( $p=0.003$ by multiple ANOVA, using transgene and drug as variables). Tamoxifen used the same way did not have a significant effect on RVSP, but RVSP trended downwards. Each symbol represents a value from one mouse. $c$ ) $A+F$ used as treatment nearly normalised the increase in muscularised vessels normally seen in BMPR2 ${ }^{\text {899X }}$ mice; tamoxifen had intermediate effect. By ANOVA, BMPR2 mutation increases muscularised vessels ( $p=0.0004)$ while $A+F(p=0.0004)$ and tamoxifen ( $p=0.02)$ both decrease them. $d)$ Ceramide (toxic lipid) staining (brown) is increased in lungs from BMPR2 ${ }^{\mathrm{R} 899 \mathrm{X}}$ mice, and reduced by A+F, but not by tamoxifen. Scale bar=25 $\mu \mathrm{m}$.

ESR1 or ESR2. Thus, these mice each had two transgenes and two knockout alleles (Rosa26-rtTA2M2, TetO7-Bmpr2 ${ }^{\mathrm{R} 899 \mathrm{X}}$, and two alleles knocked out of either ESR1 or ESR2). Adult animals were fed doxycycline for 6 weeks to induce Bmpr2 $2^{\mathrm{R} 89 \mathrm{X}}$ transgene expression.

As expected, ESR1 but not ESR2 knockout resulted in reduction in uterine weight (figure 3a) [33]. Western blots for ESR1, ESR2, and the noncanonical G protein coupled estrogen receptor (GPER) in ESR1 and ESR2 knockout and heterozygous mice show the expected and specific loss of protein (online supplementary figure S3). There appears to be a compensatory increase in GPER, but not the reciprocal ESR, with either ESR1 or ESR2 knockout.

Closed-chest measurement of RVSP in spontaneously breathing mice found 20 (54\%) out of 37 $\mathrm{Bmpr} 2^{\mathrm{R} 899 \mathrm{X}}$ mice with pressures $>32 \mathrm{mmHg}$ (figure $3 \mathrm{~b}$ ), while this number was lower in $\mathrm{Bmpr} 2^{\mathrm{R} 899 \mathrm{X}}$ mice with ESR1 knockout (seven (33\%) out of 21 ), and three (14\%) out of 22 in Bmpr2 ${ }^{\text {R899X }}$ mice with ESR2 knockout. The trend was similar for muscularisation, with numbers of muscularised small vessels in $\mathrm{Bmpr} 2^{\mathrm{R} 899 \mathrm{X}}$ mice nearly double that of controls (figure $3 \mathrm{c}$ and $\mathrm{d}$ ), and these numbers reduced somewhat in ESR1 and more in ESR2 knockouts. The occluded vessels that can occasionally be seen in Bmpr2 $2^{\mathrm{R} 899 \mathrm{X}}$ mouse lungs were still present in ESR1 knockouts, but not apparent in ESR2 knockouts (figure 3d). Taken 


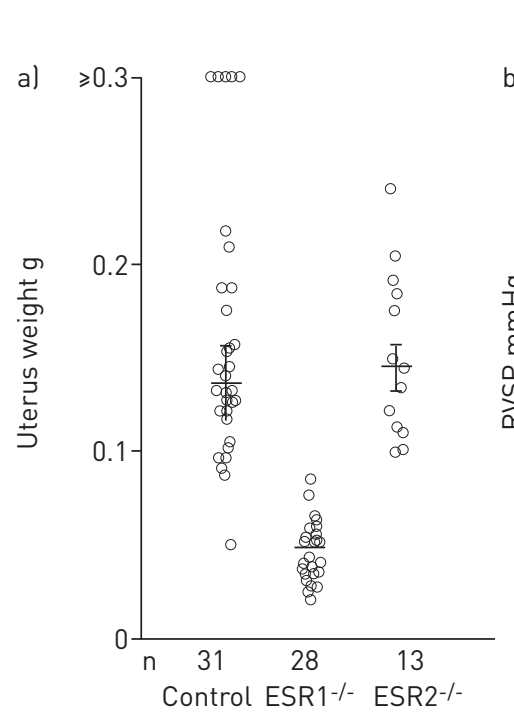

d)
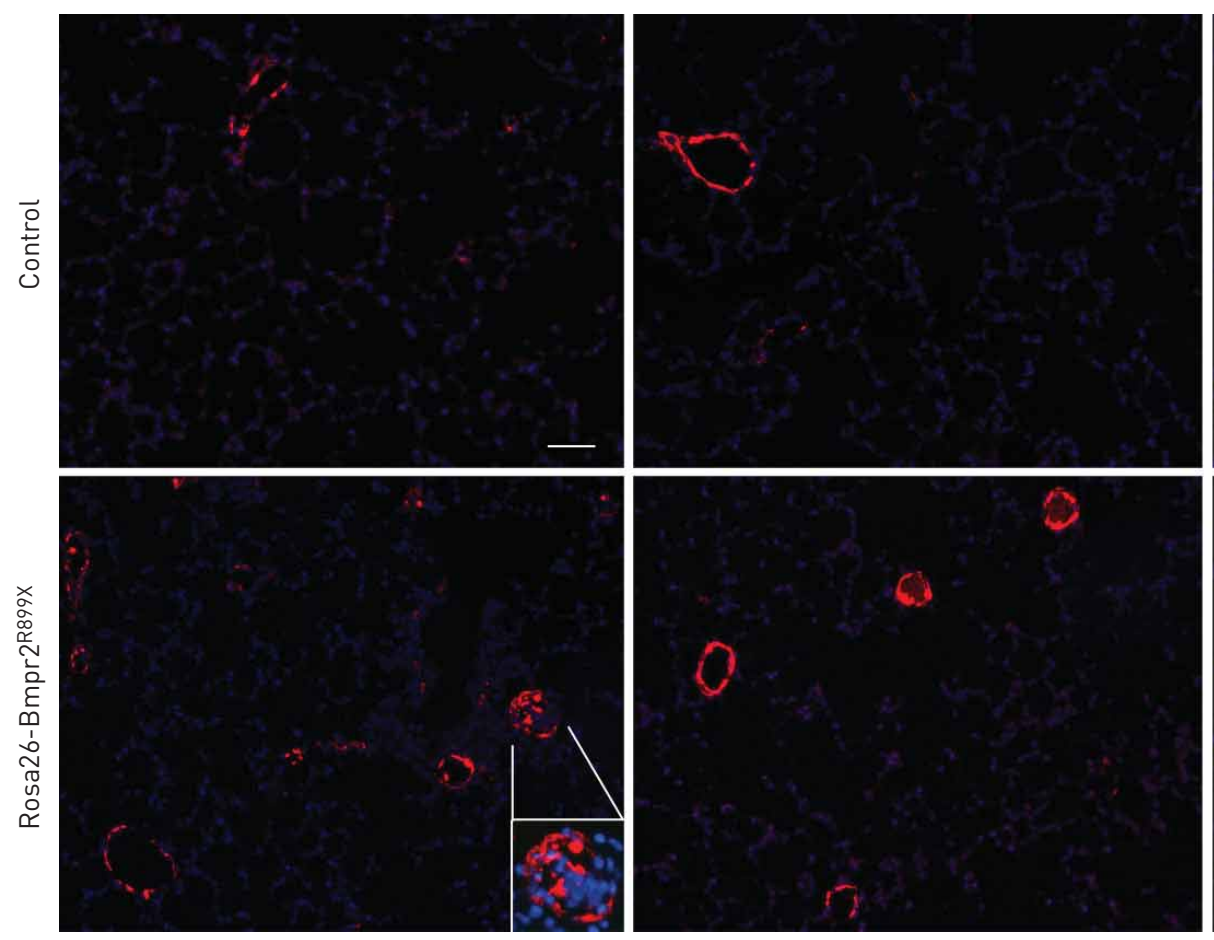

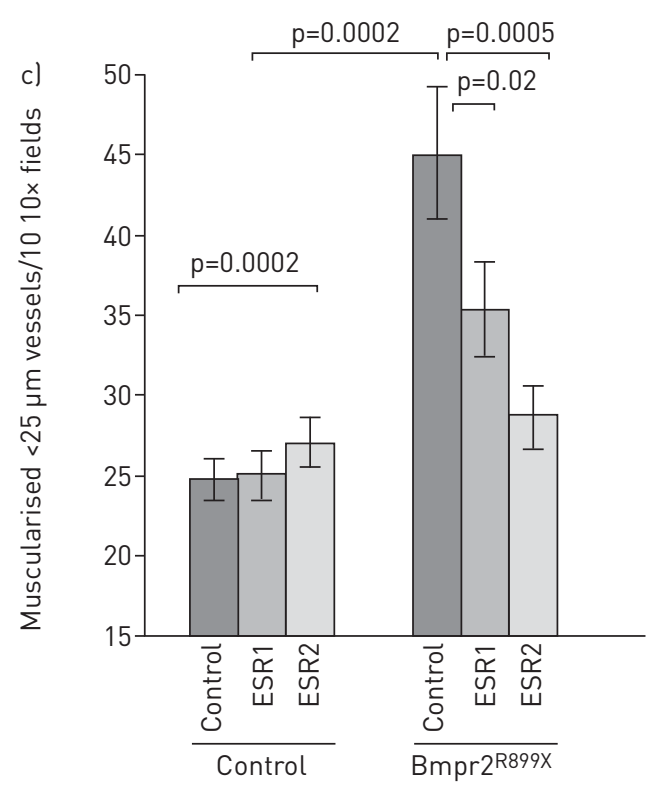

ESR2 knockout
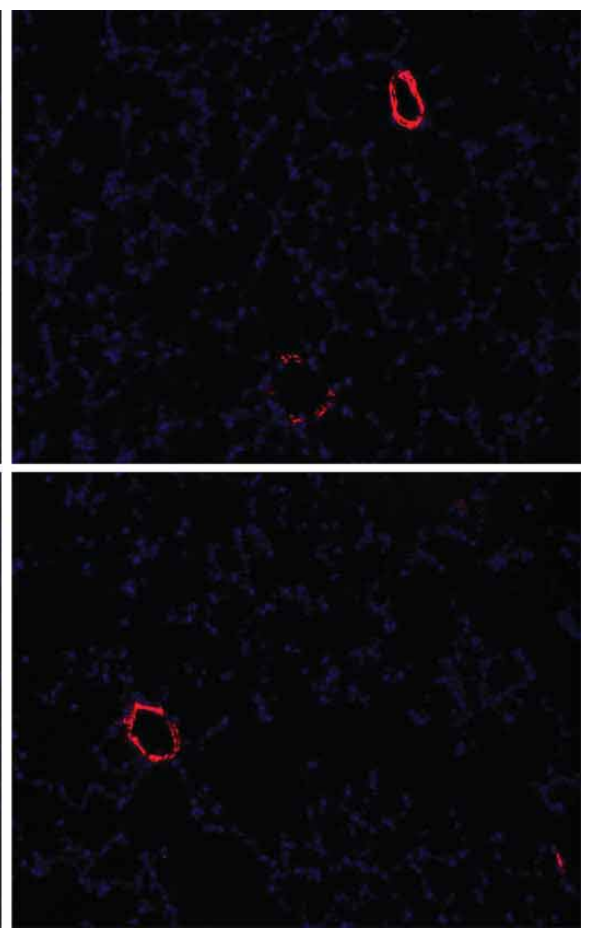

FIGURE 3 a) Oestrogen receptor (ESR)1, but not ESR2 knockout reduces uterine weights in mice ( $p<0.0001$ ), as expected [33]; by multiple ANOVA, R899X mutation did not have an effect on uterine weight. Each symbol represents the measurement from one mouse; data are presented as median \pm SEM. b) ESR1 knockout partially and ESR2 knockout completely reduces right ventricular systolic pressure (RVSP) in both male and female BMPR2 ${ }^{R 899 X}$ mice. Each symbol represents a value from one mouse. By multiple ANOVA, considering sex, BMPR2 mutation and ESR status as factors, BMPR2 mutation increases RVSP ( $p=0.0003$ by multivariate ANOVA), ESR1 trends towards restoration ( $p=0.07$ ) and ESR2 completely restores ( $p=0.005$ ) RVSP. Sex did not have significant interaction (all mice received $16 \alpha$ OHE1 in pumps). Numbers of mice in each group are listed at the bottom of the plot; mice were age-matched, and controls assessed contemporaneously for each group. c) ESR1 knockout mice partially and ESR2 knockout mice completely reduce muscularised small vessels in BMPR2 ${ }^{R 899 X}$ mice to normal. By multiple ANOVA, considering sex, BMPR2 mutation and ESR status as factors, BMPR2 mutation increases muscularised vessels ( $p=0.0002$ by multivariate ANOVA) and both ESR1 ( $p=0.02$ ) and ESR2 ( $p=0.0005$ ) normalise muscularised vessels. d) Immunohistochemistry for smooth muscle actin (red) counterstained with 4',6-diamidino-2-phenylindole (DAPI; blue). Apparent intensity of DAPI staining has been reduced to clarify actin. Muscularised and partially muscularised small vessels are roughly doubled in BMPR2 ${ }^{R 899 X}$ mice, and there is the occasional occluded vessel (inset). ESR1 knockout reduces muscularisation, but still has some occluded vessels (top two in field); ESR2 knockout normalises muscularisation, and occluded vessels are no longer apparent. 
together, these data suggest that the effects of oestrogen in PAH are mediated partially through both ESR1 and ESR2, with ESR2 predominating.

\section{Oestrogen inhibition reverses BMPR2 mutation-induced insulin resistance}

We and others have previously shown that PPAR- $\gamma$ and CD36 expression are suppressed in BMPR2 mutant mice and human PAH patients and insulin resistance is increased [22, 34].

Here we found that these changes were prevented (figure 4a) and reversed (figure $4 \mathrm{~b}$ ) by oestrogen inhibition. Suppression of PPAR- $\gamma$ and CD36 in the vehicle BMPR2 mutant groups is more impressive in the reversal study, presumably because the animals have had longer to develop disease (10 weeks rather than 6 weeks). Measurement of insulin resistance by measurement of blood glucose and insulin showed, as before, a strong increase in homeostatic model assessment (HOMA) insulin resistance in BMPR2 mutants, substantially reduced by anastrozole/fulvestrant, and trending down with tamoxifen (figure 4c). Plotting HOMA insulin resistance against RVSP shows that the two are strongly correlated ( $\mathrm{r}=0.71$ ) (figure $4 \mathrm{~d}$ ). These data suggest that the effect of oestrogen inhibition on RVSP is closely correlated with its metabolic effects.

In addition, we measured PPAR- $\gamma$ and CD36 in ESR1 and ESR2 knockout mice with and without BMPR2 mutation. ESR1 knockout did not have a consistent effect (figure 5a), while ESR2 knockout led to increased PPAR- $\gamma$ and CD36 in both control and BMPR2 mutant mice (figure 5b). This supports the haemodynamic measurements in figure 3, which suggested that ESR2 is more responsible for the negative effects of oestrogen in PAH than ESR1.

\section{Oestrogen drives insulin resistance on a cellular level}

Although glucose metabolism is regulated on a whole-organism level by the interaction of multiple organs, on a cellular level, insulin resistance is characterised by reduced mobilisation of the glucose transporter Glut4 in response to insulin. We have previously shown a basic defect at this level in BMPR2 mutant human endothelial cells; specifically, insulin signalling is intact but Glut4 fails to mobilise [35]. Here we replicate that result, and show that oestrogenic $16 \alpha \mathrm{OHE} 1$ significantly worsens the insulin response in PMVECs cultured from Bmpr2 ${ }^{\mathrm{R} 899 \mathrm{X}}$ mice (figure $6 \mathrm{a}$ and b). $16 \alpha \mathrm{OHE} 1$ was used instead of E2, because it is more oestrogenic than E2, and E2 in patients is preferentially metabolised to $16 \alpha \mathrm{OHE} 1$ [11].

Comparing maximum oxygen consumption rate (OCR) in $\mathrm{Bmpr} 2^{\mathrm{R} 899 \mathrm{X}}$ PMVEC compared to wild-type PMVEC using Seahorse extracellular flux analysis, we found that PMVECs from Bmpr $2^{\mathrm{R} 899 \mathrm{X}}$ mice have a significantly lower maximum OCR (figure $6 c$ and d) in standard media. However, the addition of $16 \alpha \mathrm{OHE} 1$ increases maximum OCR in Bmpr $2^{\mathrm{R} 899 \mathrm{X}}$ mutants; in contrast, $16 \alpha \mathrm{OHE} 1$ lowers maximum OCR in wild-type cells (figure $6 \mathrm{c}$ and $\mathrm{d}$ ). These data suggest that oestrogens modify the already perturbed cellular metabolic activity in the Bmpr2 mutant setting.

Although we do not know in detail how oestrogen impacts metabolism in these cells, staining live cells with the superoxide detector Mitosox Red suggests that increased oxygen consumption with $16 \alpha \mathrm{OHE} 1$ is caused by increased superoxide production (figure 6e).

\section{Discussion}

Over the past decade, the PAH research community has made tremendous strides towards developing molecularly targeted therapies. There is broad consensus in the field that in addition to, or perhaps because of, suppressed BMP signalling, progression of PAH requires dedifferentiation and proliferation, inflammation and metabolic changes. Trials targeting each of these have either been completed [36-38], are in progress [39] or are in development [40]; at this point the debate is how to effectively intervene, rather than where we need to intervene. The field is thus in a state in which our goal is effectively translating our molecular findings into treatments.

Female sex is the strongest epidemiological risk factor for PAH, with a 3:1 female:male ratio. However, until recently, the reasons for this were unclear: oestrogen and female sex were protective in classical PAH models such as hypoxia and monocrotaline [15]. However, a chain of research has contributed new information regarding sex and PAH. PAH patients have increased level of oestradiol [41], while increased risk of PAH in patients is strongly associated with preferential metabolism of oestrogens into 16-oestrogens such as $16 \alpha \mathrm{OHE} 1[11,12,42]$. There are underlying genetic variations in both aromatases, which produce parent oestrogens [41] and in CYP1B1, which modulates oestrogen metabolism [11, 43] associated with outcomes in both portopulmonary and idiopathic pulmonary hypertension. Increase in $16 \alpha \mathrm{OHE} 1$ is important because it covalently binds the receptor and is thus much more oestrogenic than 2- and 4-oestrogens.

Treating BMPR2 mutant mice with $16 \alpha \mathrm{OHE} 1$ increases penetrance and severity of disease [14], associated with markers of increased metabolic problems [17]. Markers of metabolic derangements, including the 
a)
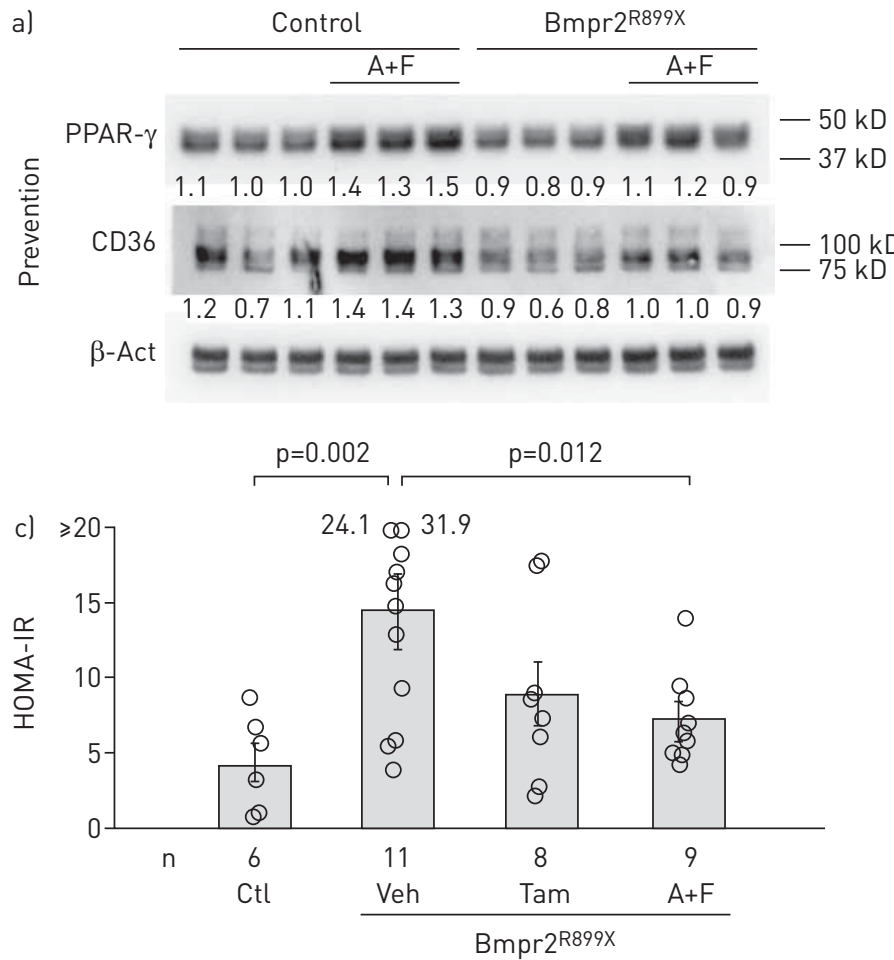

b)

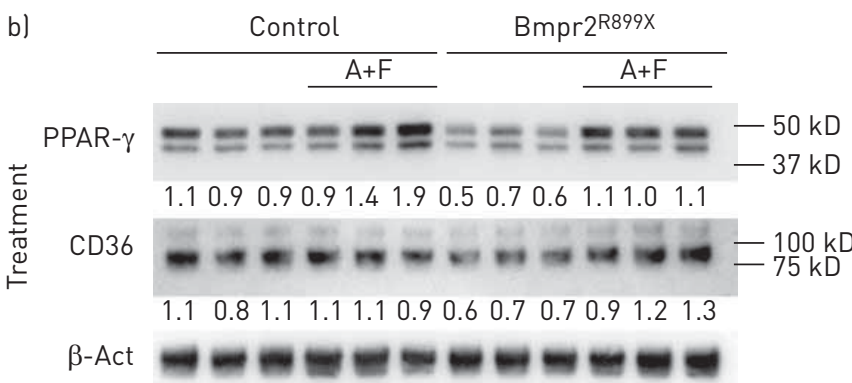

d) 35 o Rosa26-only control

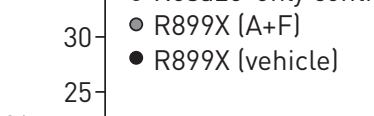

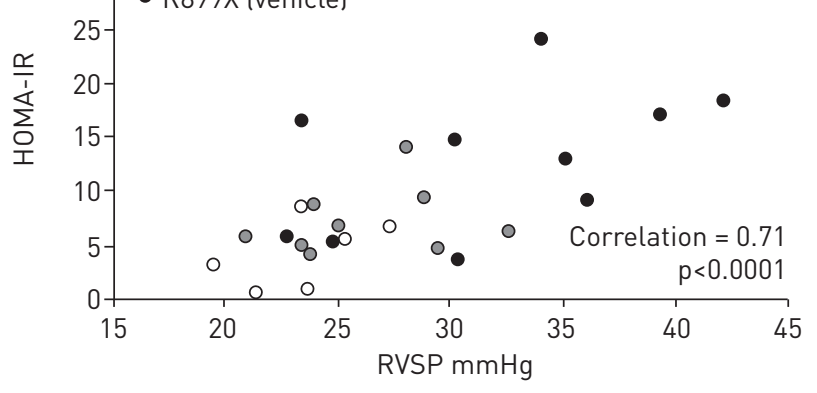

FIGURE 4 a) Anastrozole and fulvestrant $(A+F)$ used preventatively result in increased peroxisome proliferator-activated receptor (PPAR)- $\gamma$ ( $p=0.001$ ) and CD36 ( $p=0.02$ ) in whole lung, which are otherwise suppressed by R899X mutation ( $p=0.003$ for PPAR- $\gamma$ and $p=0.007$ for CD36) by two-way ANOVA. Numbers represent densitometry for the bands above; each lane is whole lung from a different animal. b) A+F used as treatment result in increased PPAR- $\gamma(p=0.019)$ and $\operatorname{CD} 36(p=0.027)$ in whole lung, which are otherwise suppressed by R899X mutation ( $p=0.047$ for PPAR- $\gamma$ and $p=0.043$ for CD36) by two-way ANOVA. Numbers represent densitometry for the bands above; each lane is whole lung from a different animal. c) $A+F$ used as a treatment significantly reduce insulin resistance in R899X mice ( $p=0.012$ ), while tamoxifen (Tam) trends towards improvement $(p=0.06)$. Tests are Fisher's least significant difference after ANOVA ( $p=0.01$ for rejection of null). Note that insulin resistance even in control mice is quite high, as they are FVB/N mice on a Western diet. d) Insulin resistance is highly correlated with right ventricular systolic pressure (RVSP) Icorrelation=0.71, $\mathrm{p}<0.0001$ ). $\beta$-Act: $\beta$-actin; HOMA-IR: homeostatic model assessment insulin resistance ctl: control; veh: vehicle.

metabolic syndrome, are strongly associated with disease in patients [18-20] and are causal in BMPR2 mutant mice [21, 22]. Metabolic problems may be important on their own, for instance, by facilitating proliferation, but they may also be important because they result in increased production of reactive oxygen and nitrogen species. These phenomena are heavily interlinked, and both have been extensively studied in PAH (reviewed by FESSEL and WEST [44]). Oestrogens, and in particular 16 $\alpha \mathrm{OHE1}$, have recently been shown to induce reactive oxygen species production in an NADPH-dependent fashion [45], supporting the link between oestrogens, metabolism and reactive oxygen species.

In the present study, we finalise preparations for translation by addressing key remaining issues. We demonstrate that oestrogen inhibition both prevents and reverses PAH in the context of BMPR2 mutation,
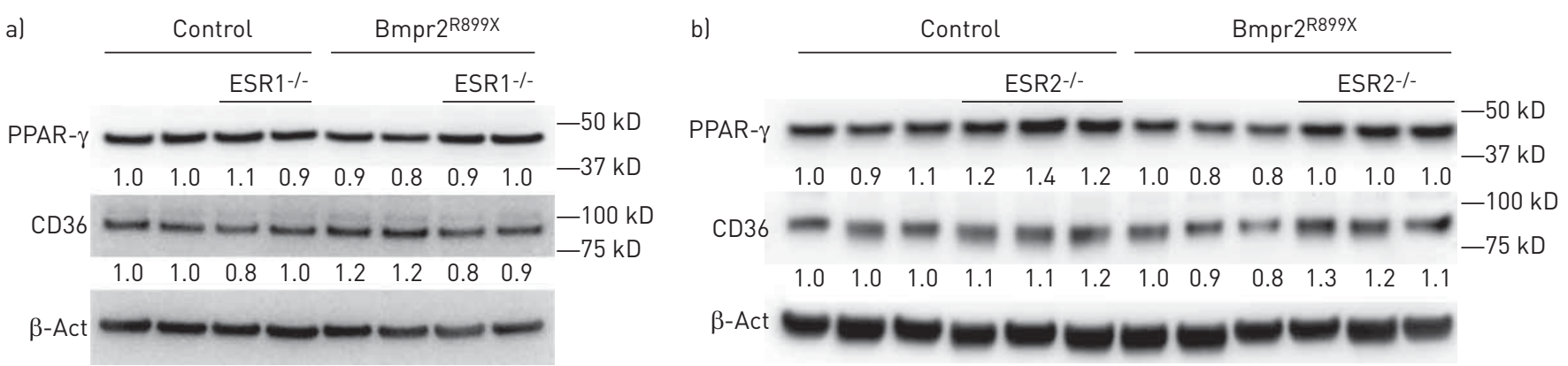

$\beta$-Act

FIGURE 5 a) By two-way ANOVA, oestrogen receptor (ESR)1 knockout does not affect peroxisome proliferator-activated receptor (PPAR)- $\gamma$ or CD36 in whole lung, although PPAR- $\gamma$ is suppressed by R899X mutation ( $p=0.03$ ). b) By two-way ANOVA, PPAR- $\gamma$ is suppressed by R899X mutation ( $p=0.02$ ) in whole lung and induced by ESR2 knockout ( $p=0.001)$; CD36 is also induced by ESR2 knockout ( $p=-0.001)$. $\beta$-Act: $\beta$-actin. 

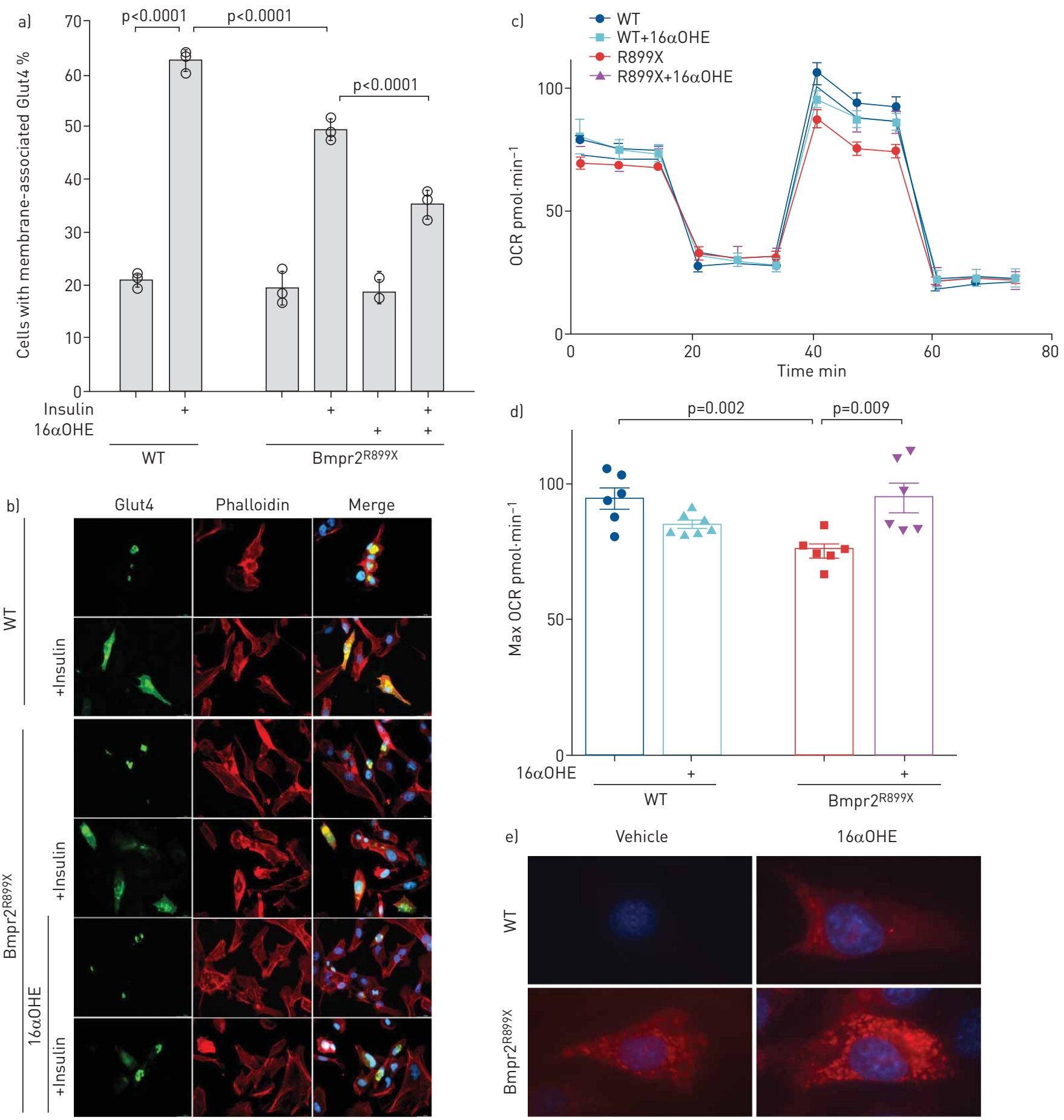

FIGURE 6 a) Insulin mobilisation of GLUT4 in mouse pulmonary microvascular endothelial cells (PMVECs) is decreased in BMPR2 ${ }^{\text {R899X }}$ mice, and decreased further by pretreatment with $16 \alpha \mathrm{OHE} 1$. Insulin mobilisation was determined by counting perinuclear versus membrane-associated green fluorescent protein (GFP)-tagged GLUT4 in each of 100 cells in each of three technical replicates (percentage in each replicate indicated by circles). Every group has three technical replicates: some are overlapping. Error bars represent standard deviation; differences are significant at $p<0.0001$ by ANOVA, with comparisons indicated by Fisher's least significant difference. Differences are significant by Wilcoxon nonparametric test $(p=0.01)$. b) Live cell images of mouse PMVECs transiently transfected with GFP-tagged Glut4, untreated and pretreated with $16 \alpha 0 \mathrm{HE} 1$, either with vehicle or $15 \mathrm{~min}$ after treatment with insulin (which ought to mobilise Glut4 to the cell surface). c) Seahorse Extracellular Flux analysis (Seahorse Biosciences, North Billerica, MA, USA) using the mito stress protocol shows an increase in maximum oxygen consumption rate (OCR) with FCCP treatment ( 40-60 min). d) Quantitation of maximum oxygen consumption rate from data in c). e) A Mitosox Red assay (Molecular Probes, Eugene, OR, USAl suggests that the increased oxygen consumption in Bmpr2 mutant cells with $16 \alpha \mathrm{OHE} 1$ is driven by increased mitochondrial superoxide production. WT: wild-type. 
probably through canonical oestrogen receptor signalling. We show that oestrogen inhibition reverses markers of metabolic defects including HOMA-insulin resistance, and that oestrogen impacts insulin resistance on a cellular level. The combination of these data provides a possible mechanism of action, and demonstrates efficacy in mice, paving the way for clinical trials in patients using oestrogen inhibition to impact the metabolic axis.

A key question is whether the oestrogen is modulating metabolism directly, or indirectly through modulation of the BMP pathway. Oestrogen suppresses BMPR2 signalling in human pulmonary artery smooth muscle cells [46], possibly by direct binding of the oestrogen receptor to the BMPR2 promoter [47], which can lead to increased proliferation in cell culture. Since the BMP pathway regulates metabolism, at least some of the effect may be through ESR1 $(\mathrm{ER} \alpha)$-mediated suppression of BMPR2. ESR1 single-nucleotide polymorphisms have previously been associated with pulmonary hypertension risk in portopulmonary hypertension [41]. However, some of the effect may be direct; ESR2 (ER $\beta$ ) can localise to the mitochondria, where it directly forces a metabolic shift supportive of proliferation [48]. Since we have previously a shown a strong impact of oestrogen on mitochondrial morphology [17], it is likely that at least part of the oestrogen effect on metabolism bypasses BMPR2. Because both ESR1 and ESR2 have plausible and distinct modes of action, the dominant effects is probably exquisitely dependent on the precise conditions and organ under investigation. For instance, in the present study, since BMPR2 is genetically suppressed, the role of ESR1 in suppressing BMPR2 may be less important. The increase in GPER with ESR knockout may be relevant to outcomes as well: GPER has been shown to increase with pharmacological oestrogen blockade [49]. Increased signalling through GPER has potential benefits in PAH [50].

Another interesting point is the question of whether the source of the oestrogens is important. Most previous studies showing a protective effect of oestrogen used male rodents administered exogenous oestrogen; by contrast, anastrozole is protective in female but not male rodents using either hypoxia or Sugen/hypoxia models [16]. Moreover, only female mice develop pulmonary hypertension in the dexfenfluramine model [51], and ovariectomy prevents pulmonary hypertension in mice overexpressing the serotonin transporter [52]. The theory is that the site of oestrogen production is important, and that extragonadal oestrogen production may be of particular importance. In support of this, we have previously shown that mode of oestrogen metabolism correlates with disease penetrance in male PAH patients as well [17]. This suggests that in male and postmenopausal patients, peripheral oestrogen production, for instance in adipose tissue [53], may still be a pathological source of oestrogen driving disease.

These and other scientific questions remain to be addressed. In the long term, oestrogens may have a protective impact upon the function of the right ventricle in humans with $\mathrm{PAH}$, which remains an opportunity for further study $[43,54-56]$. Although clearly neither oestrogen nor insulin resistance alone is enough to cause $\mathrm{PAH}$, as the vast majority of females and diabetics do not develop PAH, in the context of BMPR2 mutation these are strong drivers of progression to clinical disease. However, we still don't understand the mechanisms in detail. Exposure to oestrogens and exposure to a BMPR2 mutation are associated with fragmented mitochondria [17], increased oxidative stress [57], alterations in protein, sugar and lipid handling [18] and increased insulin resistance [14, 22]. Although all of these phenomena are related, we don't as yet have a top-to-bottom mechanism linking these to either oestrogen or BMPR2, and we don't know which of these are pathogenic and which are bystanders. In addition, we don't know the precise contribution, if at all, of noncanonical oestrogen signalling.

While scientifically interesting, it is not mandatory to answer all of these questions before proceeding to translation. Particularly in males and in postmenopausal females, strong oestrogen inhibition is safe, addresses many molecular pathologies causally linked to development of PAH and reverses established disease in mice carrying the same BMPR2 mutation found in many patients. In fact, a short phase II human $\mathrm{PAH}$ trial using a form of oestrogen modification was recently completed (clinicaltrials.gov identifier NCT01545336); it was safe, well tolerated, and showed hints of efficacy [24]. One of the central questions in clinical translation is which drug to use. Our data suggest that while stronger inhibition, such as that achieved by anastrozole and fulvestrant, is more effective, and thus probably preferable for postmenopausal patients and males, tamoxifen has some efficacy, and as it is easier to use in premenopausal females [58], it is worth determining whether it can be substituted in these younger patients in order to avoid induction of menopause.

The present study contributes critical background work to further demonstrate the efficacy of oestrogen inhibition and to elucidate mechanisms including improvement in some metabolic irregularities present in PAH. By adding to the groundwork needed to proceed to human trials, we look forward to proceeding with additional testing and early translational studies. 


\section{References}

1 de Jesus Perez VA. Molecular pathogenesis and current pathology of pulmonary hypertension. Heart Fail Rev 2016; 21: 239-257.

2 Stacher E, Graham BB, Hunt JM, et al. Modern age pathology of pulmonary arterial hypertension. Am J Respir Crit Care Med 2012; 186: 261-272.

3 Cogan JD, Vnencak-Jones CL, Phillips JA 3rd, et al. Gross BMPR2 gene rearrangements constitute a new cause for primary pulmonary hypertension. Genet Med 2005; 7: 169-174.

4 Rajkumar R, Konishi K, Richards TJ, et al. Genomewide RNA expression profiling in lung identifies distinct signatures in idiopathic pulmonary arterial hypertension and secondary pulmonary hypertension. Am J Physiol Heart Circ Physiol 2010; 298: H1235-H1248.

5 West J, Fagan K, Steudel W, et al. Pulmonary hypertension in transgenic mice expressing a dominant-negative BMPRII gene in smooth muscle. Circ Res 2004; 94: 1109-1114.

6 West J, Harral J, Lane K, et al. Mice expressing BMPR2R899X transgene in smooth muscle develop pulmonary vascular lesions. Am J Physiol Lung Cell Mol Physiol 2008; 295: L744-L755.

7 Hong $\mathrm{KH}$, Lee YJ, Lee E, et al. Genetic ablation of the BMPR2 gene in pulmonary endothelium is sufficient to predispose to pulmonary arterial hypertension. Circulation 2008; 118: 722-730.

8 Soon E, Crosby A, Southwood M, et al. Bone morphogenetic protein receptor type II deficiency and increased inflammatory cytokine production. A gateway to pulmonary arterial hypertension. Am J Respir Crit Care Med 2015; 192: 859-872.

9 Lahm T, Tuder RM, Petrache I. Progress in solving the sex hormone paradox in pulmonary hypertension. Am $J$ Physiol Lung Cell Mol Physiol 2014; 307: L7-L26.

10 Larkin EK, Newman JH, Austin ED, et al. Longitudinal analysis casts doubt on the presence of genetic anticipation in heritable pulmonary arterial hypertension. Am J Respir Crit Care Med 2012; 186: 892-896.

11 Austin ED, Cogan JD, West JD, et al. Alterations in oestrogen metabolism: implications for higher penetrance of familial pulmonary arterial hypertension in females. Eur Respir J 2009; 34: 1093-1099.

12 West J, Cogan J, Geraci M, et al. Gene expression in BMPR2 mutation carriers with and without evidence of pulmonary arterial hypertension suggests pathways relevant to disease penetrance. BMC Med Genomics 2008 ; $1: 45$.

13 White K, Johansen AK, Nilsen M, et al. Activity of the estrogen-metabolizing enzyme cytochrome P450 $1 \mathrm{~B} 1$ influences the development of pulmonary arterial hypertension. Circulation 2012; 126: 1087-1098.

14 Fessel JP, Chen X, Frump A, et al. Interaction between bone morphogenetic protein receptor type 2 and estrogenic compounds in pulmonary arterial hypertension. Pulm Circ 2013; 3: 564-577.

15 Lahm T, Albrecht M, Fisher AJ, et al. 17 $\beta$-Estradiol attenuates hypoxic pulmonary hypertension via estrogen receptor-mediated effects. Am J Respir Crit Care Med 2012; 185: 965-980.

16 Mair KM, Wright AF, Duggan N, et al. Sex-dependent influence of endogenous estrogen in pulmonary hypertension. Am J Respir Crit Care Med 2014; 190: 456-467.

17 Chen X, Talati M, Fessel JP, et al. Estrogen metabolite $16 \alpha$-hydroxyestrone exacerbates bone morphogenetic protein receptor type II-associated pulmonary arterial hypertension through microRNA-29-mediated modulation of cellular metabolism. Circulation 2016; 133: 82-97.

18 Fessel JP, Hamid R, Wittmann BM, et al. Metabolomic analysis of bone morphogenetic protein receptor type 2 mutations in human pulmonary endothelium reveals widespread metabolic reprogramming. Pulm Circ 2012; 2: 201-213.

19 Hemnes AR, Brittain EL, Trammell AW, et al. Evidence for right ventricular lipotoxicity in heritable pulmonary arterial hypertension. Am J Respir Crit Care Med 2014; 189: 325-334.

20 Pugh ME, Robbins IM, Rice TW, et al. Unrecognized glucose intolerance is common in pulmonary arterial hypertension. J Heart Lung Transplant 2011; 30: 904-911.

21 Fessel JP, Flynn CR, Robinson LJ, et al. Hyperoxia synergizes with mutant bone morphogenic protein receptor 2 to cause metabolic stress, oxidant injury, and pulmonary hypertension. Am J Respir Cell Mol Biol 2013; 49: $778-787$.

22 West J, Niswender KD, Johnson JA, et al. A potential role for insulin resistance in experimental pulmonary hypertension. Eur Respir J 2013; 41: 861-871.

23 Ryan JJ, Archer SL. Emerging concepts in the molecular basis of pulmonary arterial hypertension: part I: metabolic plasticity and mitochondrial dynamics in the pulmonary circulation and right ventricle in pulmonary arterial hypertension. Circulation 2015; 131: 1691-1702.

24 Kawut SM, Archer-Chicko CL, DeMichele A, et al. Anastrozole in pulmonary arterial hypertension. a randomized, double-blind, placebo-controlled trial. Am J Respir Crit Care Med 2017; 195: 360-368.

25 Johnson JA, Hemnes AR, Perrien DS, et al. Cytoskeletal defects in Bmpr2-associated pulmonary arterial hypertension. Am J Physiol Lung Cell Mol Physiol 2012; 302: L474-L484.

26 Yasuda T, Tada Y, Tanabe N, et al. Rho-kinase inhibition alleviates pulmonary hypertension in transgenic mice expressing a dominant-negative type II bone morphogenetic protein receptor gene. Am J Physiol Lung Cell Mol Physiol 2011; 301: L667-L674.

27 Reagan-Shaw S, Nihal M, Ahmad N. Dose translation from animal to human studies revisited. FASEB J 2008; 22 659-661.

28 Spurney CF, Knoblach S, Pistilli EE, et al. Dystrophin-deficient cardiomyopathy in mouse: expression of Nox4 and Lox are associated with fibrosis and altered functional parameters in the heart. Neuromuscul Disord 2008; 18: $371-381$.

29 Tanaka N, Dalton N, Mao L, et al. Transthoracic echocardiography in models of cardiac disease in the mouse Circulation 1996; 94: 1109-1117.

30 Majka S, Hagen M, Blackwell T, et al. Physiologic and molecular consequences of endothelial Bmpr2 mutation. Respir Res 2011; 12: 84.

31 Talati M, Hemnes A. Fatty acid metabolism in pulmonary arterial hypertension: role in right ventricular dysfunction and hypertrophy. Pulm Circ 2015; 5: 269-278.

32 Itoh T, Karlsberg K, Kijima I, et al. Letrozole-, anastrozole-, and tamoxifen-responsive genes in MCF-7aro cells: a microarray approach. Mol Cancer Res 2005; 3: 203-218. 
33 Couse JF, Curtis Hewitt S, Korach KS. Receptor null mice reveal contrasting roles for estrogen receptor $\alpha$ and $\beta$ in reproductive tissues. J Steroid Biochem Mol Biol 2000; 74: 287-296.

34 Zamanian RT, Hansmann G, Snook S, et al. Insulin resistance in pulmonary arterial hypertension. Eur Respir J 2009; 33: 318-324.

35 Trammell A, Talati M, Brittain E, et al. BMPR2 mutation results in impaired GLUT4 trafficking. Am J Respir Crit Care Med 2013; 187: A1735.

36 Hansmann G, Wagner RA, Schellong S, et al. Pulmonary arterial hypertension is linked to insulin resistance and reversed by peroxisome proliferator-activated receptor- $\gamma$ activation. Circulation 2007; 115: 1275-1284.

37 Frost AE, Barst RJ, Hoeper MM, et al. Long-term safety and efficacy of imatinib in pulmonary arterial hypertension. J Heart Lung Transplant 2015; 34: 1366-1375.

38 Bonnet S, Archer SL, Allalunis-Turner J, et al. A mitochondria- $\mathrm{K}^{+}$channel axis is suppressed in cancer and its normalization promotes apoptosis and inhibits cancer growth. Cancer Cell 2007; 11: 37-51.

39 Spiekerkoetter E, Sung YK, Sudheendra D, et al. Low-dose FK506 (tacrolimus) in end-stage pulmonary arterial hypertension. Am J Respir Crit Care Med 2015; 192: 254-257.

40 Long L, Ormiston ML, Yang X, et al. Selective enhancement of endothelial BMPR-II with BMP9 reverses pulmonary arterial hypertension. Nat Med 2015; 21: 777-785.

41 Roberts KE, Fallon MB, Krowka MJ, et al. Genetic risk factors for portopulmonary hypertension in patients with advanced liver disease. Am J Respir Crit Care Med 2009; 179: 835-842.

42 Dempsie Y, MacRitchie NA, White K, et al. Dexfenfluramine and the oestrogen-metabolizing enzyme CYP1B1 in the development of pulmonary arterial hypertension. Cardiovasc Res 2013; 99: 24-34.

43 Ventetuolo CE, Mitra N, Wan F, et al. Oestradiol metabolism and androgen receptor genotypes are associated with right ventricular function. Eur Respir J 2016; 47: 553-563.

44 Fessel JP, West JD. Redox biology in pulmonary arterial hypertension (2013 Grover Conference Series). Pulm Circ 2015; 5: 599-609.

45 Hood KY, Montezano AC, Harvey AP, et al. Nicotinamide adenine dinucleotide phosphate oxidase-mediated redox signaling and vascular remodeling by $16 \alpha$-hydroxyestrone in human pulmonary artery cells: implications in pulmonary arterial hypertension. Hypertension 2016; 68: 796-808.

46 Mair KM, Yang XD, Long L, et al. Sex affects bone morphogenetic protein type II receptor signaling in pulmonary artery smooth muscle cells. Am J Respir Crit Care Med 2015; 191: 693-703.

47 Austin ED, Hamid R, Hemnes AR, et al. BMPR2 expression is suppressed by signaling through the estrogen receptor. Biol Sex Differ 2012; 3: 6.

48 Liao TL, Tzeng CR, Yu CL, et al. Estrogen receptor- $\beta$ in mitochondria: implications for mitochondrial bioenergetics and tumorigenesis. Ann NY Acad Sci 2015; 1350: 52-60.

49 Barton M. Not lost in translation: emerging clinical importance of the G protein-coupled estrogen receptor GPER. Steroids 2016; 111: 37-45.

50 Alencar AK, Montes GC, Montagnoli T, et al. Activation of GPER ameliorates experimental pulmonary hypertension in male rats. Eur J Pharm Sci 2017; 97: 208-217.

51 Dempsie Y, Morecroft I, Welsh DJ, et al. Converging evidence in support of the serotonin hypothesis of dexfenfluramine-induced pulmonary hypertension with novel transgenic mice. Circulation 2008; 117: 2928-2937.

52 White K, Dempsie Y, Nilsen M, et al. The serotonin transporter, gender, and $17 \beta$ oestradiol in the development of pulmonary arterial hypertension. Cardiovasc Res 2011; 90: 373-382.

53 Goss PE, Tye LM. Anastrozole: a new selective nonsteroidal aromatase inhibitor. Oncology 1997; 11: 1697-1703.

54 Ventetuolo CE, Ouyang P, Bluemke DA, et al. Sex hormones are associated with right ventricular structure and function: the MESA-right ventricle study. Am J Respir Crit Care Med 2011; 183: 659-667.

55 Frump AL, Goss KN, Vayl A, et al. Estradiol improves right ventricular function in rats with severe angioproliferative pulmonary hypertension: effects of endogenous and exogenous sex hormones. Am J Physiol Lung Cell Mol Physiol 2015; 308: L873-L890.

56 Liu A, Hacker T, Eickhoff JC, et al. Estrogen preserves pulsatile pulmonary arterial hemodynamics in pulmonary arterial hypertension. Ann Biomed Eng 2017; 45: 632-643.

57 Lane KL, Talati M, Austin E, et al. Oxidative injury is a common consequence of BMPR2 mutations. Pulm Circ 2011; 1: 72-83.

58 Colleoni M, Munzone E. Picking the optimal endocrine adjuvant treatment for pre-menopausal women. Breast 2015; 24: Suppl. 2, S11-S14. 